\title{
Experimental investigations into nanofinishing of micro-channels
}

\author{
Leeladhar Nagdeve*, V. K. Jain and J. Ramkumar
}
Department of Mechanical Engineering, Indian Institute of Technology Kanpur, Kanpur -208016), India
*Email: liladhar@iitk.ac.in

Miniaturization is the trend where components get very small shape and size of the mechanical, optical, electronic parts and devices. Silicon wafer in IC industries, micro channels in micro-fluidics, micro dies in forming industries, micro nozzles and fuel injectors in automobile industries need high level of surface finish because of their functional requirements. Manufacturing industries are producing these parts in large number but getting high precision and defect free surface is a challenge for them, especially in the case of micro shaped features with micro and macro components. Surface finish is one of the most important characteristics for their functionality and long life in service. Micro die and mold industries produce very complicated and intricate surfaces but final component quality depends on their surface quality. Fluid flow in complex micronano tubes is greatly affected by the surface conditions. Single crystal silicon blank has been finished using MRFF process and achieved minimum surface roughness of $8 \mathrm{~nm}$ from $1300 \mathrm{~nm}$ of the initial surface roughness [1]. Micro-channels have been finished using abrasive flow machining (AFM) process [2]. In the present research work, micro channels have been made using laser micro machining process. The widths of different micro channels were $202 \mu \mathrm{m}, 320.4 \mu \mathrm{m}$, and $366.7 \mu \mathrm{m}$ on stainless steel workpiece and the depth of around $2 \mu \mathrm{m}$. These microchannels have been finished using MRFF (Magnetorheological fluid based finishing process (see Figure 1 (a) and (b).

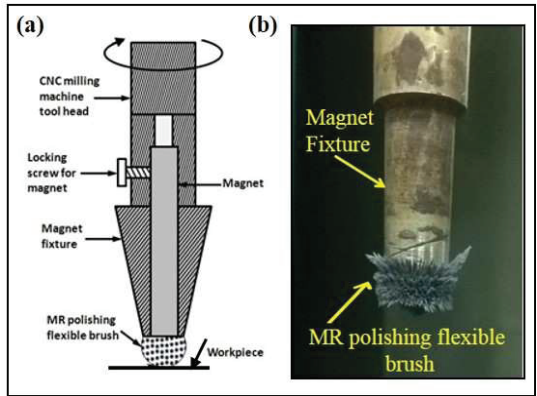

Figure 1: (a) Schematic diagram of the MRFF tool, and (b) Photograph of MRFF tool and brush

MRFF process has the potential to finish microchannels up to the nano meter range. MRFF process can also be used for nanofinishing of free form surfaces $[3,4]$. In this process, MR fluid which is used for finishing which is made up of carbonyl iron particles (CIPs), non-magnetic abrasive particles, grease and paraffin oil. When MR fluid comes in the zone of magnetic field it works as a flexible brush (see Figure $2 b$ ) and polishing takes place due to relative motion between the MRF tool and the micro-channel. Final surface roughness $\mathrm{Ra}$ value achieved on three different micro-channels were $43 \mathrm{~nm}, 34 \mathrm{~nm}, 41 \mathrm{~nm}$ which had initial surface roughness values as $216 \mathrm{~nm}$, $157 \mathrm{~nm}$, and $106 \mathrm{~nm}$, respectively as shown in Figure 2 . There are many processes available to finish microchannels but due to certain limitations, they are not applicable for finishing micro-channels and hence, the only solution is advanced finishing processes.

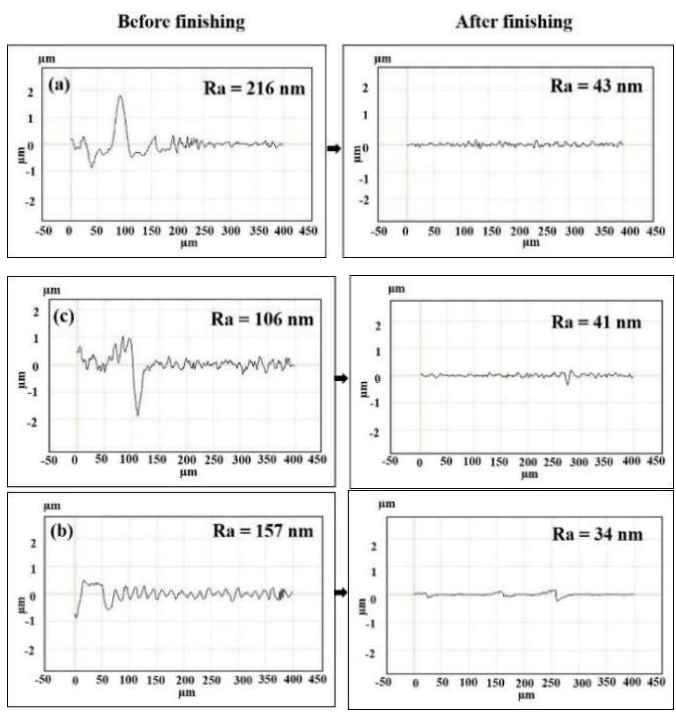

Figure 2: (a), (b), and (c) Surface roughness values of three different micro-channel (25\% CIPs, $10 \%$ Boron Carbide, 6 $\%$ grease and $59 \%$ Paraffin Oil)

\section{References}

1. A. Sidpara and V. K. Jain, Tribol Int, 47 (2012) 159-166. 2. H. J. Tzheng, B. H. Yan, R. T. Hsu and Y. C. Li, International Journal Adv. Manufacturing Technology 32 (2007) 1163-1169.

3. P. Baghel, S. Singh, L. Nagdeve, V. K. Jain and N. D. Sharma, Int. J. Precision Technology, 5 (2015) 229-245. 4. A. M. Sidpara and V. K. Jain, Part B J. Eng. Manuf, 226(11) (2012) 1833-1846. 